\title{
Allelopathic potential of stoneworts
}

\author{
Barbara MÄHNERT ${ }^{1}$, Michael SCHAGERL $^{1} \&$ Liselotte KRENN $^{2}$
}

\author{
${ }^{1}$ Department of Limnology and Bio-Oceanography, University of Vienna, Althanstrasse 14, A-1090 Vienna \\ ${ }^{2}$ Department of Pharmacognosy, University of Vienna, Althanstrasse 14, A-1090 Vienna
}

\begin{abstract}
We investigated growth inhibitory effects of the stoneworts (Characeae) Chara aspera, C. globularis, C. rudis and C. tomentosa on the target organisms Chlorella vulgaris, Acutodesmus acuminatus (Chlorophyta), Synechococcus elongatus, S. leopoliensis (Cyanobacteria) and Aliivibrio fischeri (Proteobateria). Besides fresh Chara shoots, we tested dichloromethane, $\mathrm{n}$-butanol and methanol extracts from dried algae and condensed ice from the lyophilisation process. The study revealed a high potential of allelochemicals of stoneworts for antibiotic treatments, which could be applied in several application fields. We found minor growth inhibition of eukaryotes, but strong effects on Cyanobacteria and A. fischeri with both life algae and extracts. HPLCanalyses of the extracts revealed neither intra-, nor interspecific differences of the composition, only quantitative differences were observed. Cyanobacteria were strongly affected by polar ice extracts indicating the presence of volatile allelochemicals. Application of allelopathically active extracts caused a strong decline of maximum fluorescence yield, a measure of physiological fitness, within the first few minutes and a partial recovery after 60 to 90 minutes. A comparison of active and non-active ice extracts based on GC-MS screening revealed complex patterns for active ones, however an identification of individual compounds was beyond the scope of this study.
\end{abstract}

Key words: allelochemicals, bioassay, growth inhibition, stonewort, volatile compound

\section{INTRODUCTION}

Characeae, commonly called stoneworts, are submerged photoautotrophic multicellular macroalgae with an appearance rather similar to higher plants (McCOURT et al. 2004). Stoneworts are able to colonize different habitats, such as spring-fed brooks, lakes (also deeper layers), ponds and fluvial systems; they are found in freshwater to brackish waters. Characeae usually form monospecific submerged meadows (BERGER \& Schagerl 2004). Waterbodies with a frequent occurrence of these organisms are generally clear waters with low phytoplankton productivity and great Secchi-depths (CRAWFORD 1977; Blindow et al. 2002; PeŁechata et al. 2015; Rodrigo et al. 2015). Many members of the Characeae have a characteristic pungent smell resembling garlic due to sulphuric compounds (ANTHONI et al. 1980), which are thought to be allelopathically active (ANTHONI et al. 1980; HiLt \& Gross 2008).

According to Molisch (1937), allelopathy is defined as an either harmful or beneficial biochemical effect between two plants. It is a widely distributed phenomenon and found between terrestrial, e.g. walnut trees (ERCISLI et al. 2005), and aquatic plants, e.g.,
Myriophyllum, Elodea, Ceratophyllum and Stratiotes (KurAshov et al. 2014). Producing such alleochemicals is an advantageous strategy for being highly competitive.

Some previous investigations assessed the allelopathic activity of several macrophytes and stoneworts with respect to their potential application for restoring eutrophic water bodies (Berg et al. 1999; PAKdel et al. 2013; Rojo et al. 2013). A loss of submerged macrophyte vegetation followed by a switch to the turbid state due to eutrophication has been documented for temperate shallow lakes (BLINDOw et al. 2002; KöRNER $\&$ NiCKLISCH 2002). Replanted dominating macrophyte meadows (including stoneworts) could be useful in wetland restoration and in achieving stabilized clearwater states by reducing the growth of phytoplankton and biofilms (JEPPESEN et al. 1997; HiLt \& Gross 2008; Rojo et al. 2013; Gette-Bouvarot et al. 2015; Rodrigo et al. 2015). Another application of Characeae as ecological engineers could be growth control of harmful, toxic Cyanobacteria such as Microcystis (CHEN et al. 2012).

Allelopathic activity of Chara extracts was already demonstrated for some taxa (BERGER \& SCHAGERL 2003, 2004; HiLt \& Gross 2008), but may also occur 
in other species. In many cases Cyanobacteria and diatoms, but only sporadically Chlorophytes were negatively affected by Chara (BERger \& SCHAGERL 2003, 2004; RoJo et al. 2013). Mostly inhibitions of photosystem II activity were observed (BERGER \& SCHAGERL 2004; Hitt 2006). A promising tool is the pulse amplitude modulated (PAM)- fluorescence technique, which was already applied for vascular freshwater macrophytes (KÖRNER \& NICKLISCH 2002; JIANG et al. 2014) and marine macroalgae (GAO et al. 2014; YE et al. 2014). Numerous laboratory experiments have been carried out, but in situ allelopathy of submerged macrophytes and stoneworts is difficult to investigate. So far, only few field-studies dealing with allelopathic interactions in aquatic systems have been published (ForSBERG et al. 1990; Gross et al. 2007; Hitt et al. 2012).

Another point of discussion regards species specificity of allelopathic interactions between submerged macrophytes and target organisms (VAN DONK \& VAN DE Bund 2002; Hilt \& Gross 2008; PAKDEL et al. 2013). Compared to monocultures, mixed cultures containing several Chara species and Myriophyllum spicatum LinNAEUS resulted in much stronger growth inhibition of phytoplankton (Rojo et al. 2013).

Beside biotic interactions, also abiotic factors influence allelopathy. Nutrient limitation is one example as it increases the sensitivity of phytoplankton to allelopathic substances released by submerged macrophytes (REIGOSA et al. 1999). Light availability is another factor influencing the degree of phytoplankton sensitivity against allelochemicals (Gross 2003b).
Mulderis et al. (2005) revealed that exudates of the vascular macrophyte Stratiotes aloides LinNAEus had a stronger effect on the growth of green algae at low irradiance compared to algae at higher irradiance.

According to Gross (2003a), allelochemicals released by submerged aquatic macrophytes into the ambient water must possess a hydrophilic character and have to be exuded at certain concentrations for reaching/influencing their target organisms (problem of dilution). Exactly these characteristics were found by BANkova et al. (2001), who focused on Chara globularis THUILLIER and found antibiotic activity of aqueous (polar) extracts. They mentioned that also volatile substances could exert allelopathic effects. Substances from a hydromethanolic extract of Chara aspera WILLDENOw had negative effects on the growth of Cyanobacteria (Berger \& Schagerl 2003). This effect was attributed to low molecular weight substances which might easily pass cyanobacterial cell membranes (Gross 1999).

Several substances of stoneworts were identified so far, and some may be also allelopathically active (Supplementary Table S2). 5-Methylthio-1,2,3trithiane and 4-methylthio-1,2-dithiolane have been isolated from Chara globularis and are assumed to be responsible for photosynthesis suppression and growth inhibition (ANTHONI et al. 1980). Both substances are thermolabile and volatile. The same substances were isolated from freshwater and brackish Chara species in a laboratory experiment (WIUM-ANDERSEN et al. 1982). Furthermore charamin, a quaternary ammonium

Table 1. Sampling sites, geographic coordinates and date of collection of the different Chara species in Austria.

\begin{tabular}{lll}
\hline Species & Date of collection & Geographic coordinates
\end{tabular}

Chara globularis THUILLIER

I. Obere Drau

29.VI.2014

II. Botanischer Garten

05.VI.2014

Chara tomentosa LinNAEus

I. Lake Attersee

22.V.+27.VII.2014

II. Lake Neusiedlersee

02.VII.2014

$47^{\circ} 48^{\prime} 13.88^{\prime \prime} \mathrm{N}, 13^{\circ} 29^{\prime} 22.45^{\prime \prime E}$

$47^{\circ} 45^{\prime} 45.43^{\prime \prime} \mathrm{N}, 16^{\circ} 45^{\prime} 12.56^{\prime \prime} \mathrm{E}$

Chara aspera Detharding ex Willdenow

I. Lake Millstättersee

28.VI.2014

II. Lake Attersee

27.VII.2014

$46^{\circ} 46^{\prime} 24.16^{\prime \prime} \mathrm{N}, 13^{\circ} 38^{\prime} 32.06^{\prime \prime} \mathrm{E}$

$47^{\circ} 52^{\prime} 56.59^{\prime \prime} \mathrm{N}, 13^{\circ} 31^{\prime} 54.00^{\prime \prime} \mathrm{E}$

\section{Chara rudis A. BRAUN in LeONHARDI}

I. Lake Lunzer Untersee

II. Lake Erlaufsee
19.VI.+ 30.VII.2014

22.VI.+ 30.VII.2014 $47^{\circ} 51^{\prime} 08.75^{\prime \prime} \mathrm{N}, 15^{\circ} 03^{\prime} 30.10^{\prime \prime} \mathrm{E}$

$47^{\circ} 47^{\prime} 22.31 " \mathrm{~N}, 15^{\circ} 16^{\prime} 34.26^{\prime \prime} \mathrm{E}$ 
salt with antibiotic activity, was isolated from Chara globularis (ANTHONI et al. 1986). ORTNER (2012) and DoBlander (2013) found considerable amounts of Ltryptophan in different stonewort species which is also known to be allelopathically active. They, however, did not perform bioassays with the identified substances. KuRAshov et al. (2014) summarised several allelopathically active compounds of submerged aquatic macrophytes belonging to aldehydes and ketones, ethers, terpenoids, phytoecdysteroids, fatty acids and other organic acids as well as aromatic hydrocarbons and phenol derivatives. Presumably more than one allelochemical of Chara aspera is responsible for growth inhibition of other algae (BERGER \& SCHAGERL 2003).

In this study, we aimed to identify intra- and interspecific allelopathic differences of four active Characean species. We searched for intergeneric differences of target organisms, which were photoautotrophic eukaryotes, cyanoprokaryotes and heterotrophic prokaryotes (possible antibiotic effects). We considered both polar and apolar Chara substances and tested two drying methods (air drying at $30{ }^{\circ} \mathrm{C}$ versus lyophilisation with a condenser temperature of $-100{ }^{\circ} \mathrm{C}$ ). To our knowledge, this is the first study which also included potential effects of volatile substances: we collected ice which condensed during the lyophilisation process and tested also ice extracts for allelopathic activity.

\section{Material ANd Methods}

Collection, treatment of fresh Chara and drying methods. Four Chara species, each from two different sampling sites in Austria, were chosen to check for their allelopathic activity (Table 1).

From each sampling site, several kilograms of fresh algae were collected either by hand (wading) or snorkelling (1-4 m water depth). To consider site-specific differences,

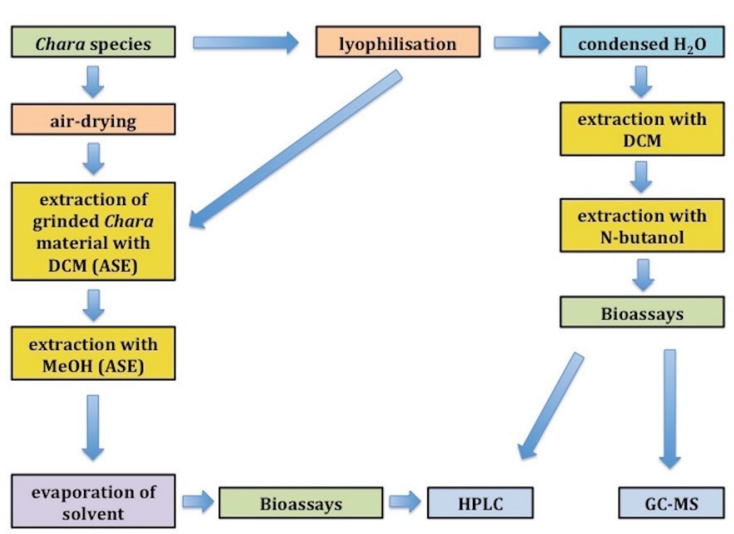

Fig.1. Workflow for extractions and analyses of extracts: (ASE) Accelerated solvent extraction machine; (DCM) dichloromethane; (GC-MS) gas chromatography combined with mass spectrometry; (HPLC) high performance liquid chromatography; $(\mathrm{MeOH})$ methanol. each species was collected from two water bodies. The collected stoneworts were identified according to the identification key of Krause (1997). Some Chara shoots were treated with some crumbs of citric acid powder or several drops of vinegar for removing calcareous layers on the cortex. Tightly attached epizoa (e.g. the molluscs Dreissena or Bithynia) were removed.

Two different drying methods were applied to compare the stability of the allelochemicals (Fig. 1). The fresh material was divided into three parts, carefully rinsed with tap water and gently spun in a salad spinner to remove attached water. One part was prepared for the freeze-dryer (Zirbus technology VaCo 2-E; condenser temperature: -100 ${ }^{\circ} \mathrm{C}$ ), one was dried in a drying cabinet at $30{ }^{\circ} \mathrm{C}$ (Binder, Art. No.: 9120-0073; 50\% ventilator-speed) and the third was used for the bioassays with living material. Before starting lyophilisation, the material was placed in a beaker glass, weighed (A\&D FY-2000) for fresh mass and frozen for several hours in a $-80{ }^{\circ} \mathrm{C}$ freezer. Before each lyophilisation, the freeze-dryer was carefully washed with several litres of Milli-Q-water to avoid cross contamination.

The dry material was then homogenised with a mortar, filled into paper bags, weighed for dry mass and stored in the $-80{ }^{\circ} \mathrm{C}$ freezer together with a desiccant in plastic boxes. Ice from the freeze dryer was thawed, collected and stored in $50 \mathrm{ml}$ Greiner tubes in the $-80^{\circ} \mathrm{C}$ freezer until use for further experiments. For determining the ash mass (inorganic fraction), 1 to $2 \mathrm{~g}$ of dried material were combusted in a muffle furnace $\left(450{ }^{\circ} \mathrm{C}\right.$ for 6 hours; Kittec XR Lehrer Thermocomputer TC 507).

Extraction with methanol $(\mathrm{MeOH})$, dichloromethane (DCM) and n-butanol. DCM (VWR, Prolabo, GPR Rectapur, No.: 25631.362) was used for extracting apolar substances, $\mathrm{MeOH}$ (p.a. quality) for the extraction of polar compounds by means of an accelerated solvent extractor (Dionex ASE 200). 5-13 g of material were filled into cartridges and extracted twice with $30 \mathrm{ml}$ of DCM followed by two extractions with $30 \mathrm{ml}$ of $\mathrm{MeOH}$ at room temperature. The two extracts with the same solvent were combined and evaporated under reduced pressure (Heidolph VV2011 with water bath WB2001; MeOH: $40{ }^{\circ} \mathrm{C}, 180-200$ mbar; DCM: $40{ }^{\circ} \mathrm{C}$, 600-650 mbar).
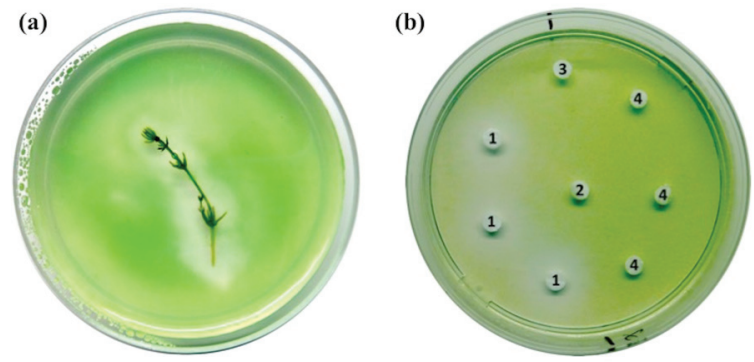

Fig. 2. (a) Example of bioassays and inhibition categories. Living shoot of Chara globularis (Obere Drau) tested on Synechococcus elongatus (inhibition intensity + ). (b) Polar extracts of lyophilised Chara rudis (Lake Erlaufsee) tested on Acutodesmus acuminatus; (1) n-butanol ice extract (inhibition intensity +++ ); (2) control filter without any extract or solvent $(\mathrm{MeOH})$; (3) control filter with evaporated $\mathrm{MeOH}$; (4) $\mathrm{MeOH}$ extract of lyophilised algae (inhibition intensity $=-$ ) 
Ice from the freeze-dryer was thawed and extracted in a first step with DCM for apolar substances (ratio 1:1) followed by a second step with n-butanol (p.a. quality) for polar substances. DCM was then removed in a Heidolph evaporator, n-butanol in a GeneVac EZ-2-Series Personal evaporator (program: Medium BP, $40{ }^{\circ} \mathrm{C}$ ). The extracts were weighed and stored in a desiccator. For further experiments and analyses, $\mathrm{n}$-butanol ice extracts were re-dissolved in $\mathrm{MeOH}$ (p.a. quality). In total 48 different extracts were available for the experiments.

Bioassays with living Chara shoots and extracts. Four different photoautotrophic microalgae strains were used as target organisms: The chlorophytes Chlorella vulgaris BEIJERINCK (SAG 211-11b, SAG = Algensammlung Universität Göttingen), Acutodesmus acuminatus LAGERHEIM (ASW 05027, (1992), ASW = Algenkultursammlung Wien) and the Cyanobacteria Synechococcus elongatus NÄGELI (SAG 89.79) and Synechococcus leopoliensis (RACIBORSKI) KOMÁREK (SAG 1402-1). These strains provided homogenous growth on both solidified inoculated agar plates and in liquid media. For excluding any growth inhibition of the target organisms by nutrient depletion, culture media with a sufficient amount of nutrients were used. C. vulgaris and A. acuminatus cultures were grown in 3NBBM medium, S. elongatus and $S$. leopoliensis in BG11 medium (both autoclaved at $120^{\circ} \mathrm{C}$ ) in a light-dark cycle of 16 to 8 hours $\left(15 \mu \mathrm{mol}\right.$ photons. $\mathrm{m}^{-2} \cdot \mathrm{s}^{-1}$ PAR) in a climate chamber at $18^{\circ} \mathrm{C}$ (SAG 2016). All bioassays with photoautotrophic target organisms were performed in petri dishes on solidified agar. Tests were conducted with non-axenic material. According to PAKDEL et al. (2013) and BERger \& SCHAGERL (2003), the presence of heterotrophic prokaryotes and other contamination of non-axenic Chara material is negligible in bioassay approaches due to their low concentration.

Healthy Chara shoots were cut off, carefully rinsed with distilled water and checked for epizoa under the binocular. For each Chara site and target species, triplicates plus one control (inoculated only with the target algae) were prepared in three steps by using plastic petri dishes according to Berger \& SChagerl (2004): first, a layer with $1 \%$ agar (Fluka Analytical, BioChemika 05039-500G; Milli-Q water) was prepared for each petri dish. Then, an agar medium with $0.2 \%$ agar (3NBBM for Acutodesmus acuminatus and Chlorella vulgaris, BG11 for Synechococcus elongatus and Synechococcus leopoliensis) was prepared, cooled down to $30{ }^{\circ} \mathrm{C}$ and inoculated with few $\mathrm{ml}$ of the target algae stock. This medium was immediately poured onto the basic agar layer. Finally, one Chara shoot per petri dish was placed onto the inoculated top agar layer and pressed down carefully to guarantee contact to the medium. The petri dishes were sealed with parafilm to minimize drying, placed in the culture room and kept at $18{ }^{\circ} \mathrm{C}, 16$ hours light, 8 hours dark at 30 $\mu \mathrm{mol}$ photons. $\mathrm{m}^{-2} \cdot \mathrm{s}^{-1} \mathrm{PAR}$. Photos of petri dishes were taken with a Sony Cybershot DSC-TX20 after 14 and 21 days, respectively. The intensity of growth inhibition of the bioassays with fresh algae and extracts was defined by the size of the surrounding clearance zone. The effects were categorised according to the strength of inhibition: - (no inhibition of microalgae growth), + (living shoot: small inhibition zone; extracts: inhibition zone around filter $<1.5 \mathrm{~mm}$ ), ++ (living shoot: about $2 / 3$ of the petri dish without microalgae growth; extracts: inhibition zone around filter 1.5 to $\leq 5.0 \mathrm{~mm}$ ) and +++ (living shoot: no microalgal growth in petri dish observable; extracts: inhibition zone around filter $>5.0 \mathrm{~mm}$ ). Two examples are shown in Figure 2a and b.

For testing the allelopathic activity of the Chara extracts, sterile glass fibre filter discs were used $(6 \mathrm{~mm}$ in diameter, Munktell MG-C; Fig. 2b). Target cultures were prepared as described above. Polar extracts, including the $\mathrm{n}-$ butanol ice extracts, were re-dissolved in $\mathrm{MeOH}$ (p.a.) and apolar extracts in DCM (p.a.) at a concentration of $5 \mathrm{mg} \cdot \mathrm{ml}^{-1}$ (referred to the weight of the dry extract crop) by sonication for 2 minutes.

For each of the 48 Chara extracts, triplicates were prepared by applying $10 \mu \mathrm{l}$ of the re-dissolved extracts on the filters with a Hamilton syringe. The filters were dried overnight in a desiccator for complete removal of the solvents. Additionally, one filter without any extract or solvent and one treated with DCM or MeOH only (10 $\mu$ l of each) were used as negative controls. Filters were placed on the second agar layer and each petri dish was sealed with parafilm. Photos were taken as described above; inhibition zones were measured with the software ImageJ 1.46r (RASBAND 1997-2014).

Extract tests on a heterotrophic, marine, bioluminescent bacterium (Aliivibrio fischeri). The LumiStox test-kit (LCK 480; Dr. Bruno Lange GmbH \& Co KG, Düsseldorf, Germany) was applied according to a standardized testing procedure in the laboratories of the Institute for Environmental Biotechnology (BOKU - IFA Tulln). The whole experimental setting followed the instructions of the manufacturer. All 48 extracts were re-dissolved in $\mathrm{MeOH}$ and tested at a concentration of $5 \mathrm{mg} \cdot \mathrm{ml}^{-1}$. For the assays, all extracts were centrifuged for 5 minutes using an Eppendorf miniSpin. 20 $\mu \mathrm{l}$ of each solution and a control of $20 \mu \mathrm{M} \mathrm{MeOH}$ were transferred into the glass cuvettes of the LumiStox-instrument and the solvents evaporated at room temperature. Positive and negative controls were included for each test run. An incubation time of 30 minutes was chosen after adding Aliivibrio fischeri to the extracts. Inhibition was defined as a $>$ $20 \%$ decrement in bioluminescence after addition of Chara extracts.

Pulse amplitude modulated (PAM) - fluorescence measurements. For testing potential effects on photosystem II (PS II) of target organisms, a Waltz measuring device was used (PAM-2500/US, ED-101US/MD, PAM-2500/US/D, PAM-2500/US/ER; software: PAMWin, Walz - Mess- und Regeltechnik, Effeltrich, Germany). The maximum quantum dark yield decreases, if an extract inhibits the target organism by affecting the PS II complex. The calculation for the maximum quantum dark yield $\left(\mathrm{F}_{\mathrm{v}} / \mathrm{F}_{\mathrm{m}}\right)$ of PS II followed the formula $F_{v} / F_{m}=\left(F_{m}-F_{0}\right) / F_{m}$ after MAXwell \& JoHNSON (2000). $\mathrm{F}_{\mathrm{m}}$ is the maximum dark fluorescence, $\mathrm{F}_{0}$ the minimum and $\mathrm{F}_{\mathrm{v}}$ the variable fluorescence.

$60 \mu \mathrm{l}$ of lyophilised Chara tomentosa $\mathrm{MeOH}$ extract (concentration of $5 \mathrm{mg} \cdot \mathrm{ml}^{-1}$ redissolved in $\mathrm{MeOH}$ ), which showed strong inhibition in preceding bioassays, was evaporated in glass tubes in a desiccator. Target algae were darkadapted for at least 15 minutes. Then $3 \mathrm{ml}$ of culture solution were added to the dried extracts. For dissolving extracts, glass tubes were carefully shaken. Triplicates were prepared for each target organism. PAM-measurements were taken at $5,15,30,60,90$ and 120 minutes incubation. As a reference, each target culture was tested without any extract and defined as $100 \%$ PS II activity.

Chromatographic analyses. Thin-layer chromatography (TLC) was performed for a first overview of the intra- and 
interspecific compositional similarity of the Chara extracts. Silica plates (Merck Analytical chromatography; TLC Silica gel $60 \mathrm{~F}_{254}$; aluminium sheets 20 x $20 \mathrm{~cm}$; No.: 1.05554.0001) were used as stationary phase. All 48 extracts were re-dissolved in $\mathrm{MeOH}$ (polar extracts) or DCM (apolar extracts) to a concentration of $5 \mathrm{mg} \cdot \mathrm{ml}^{-1} .4 \mu \mathrm{l}$ of each extract solution were spotted on the plate. Two eluent systems and two spraying reagents were used: System A for polar extracts was ethyl acetate-methanol-water (75:11:10) and System B for apolar extracts was toluene-ethyl acetate (93:7) modified after WAGNER \& BLADT (2001). Additionally, two markers $\left(0.5 \mathrm{mg} \cdot \mathrm{ml}^{-1} \mathrm{MeOH}\right)$, rutin for system $\mathrm{A}$ and quercetin for system B, were used for comparison. Anisaldehyde-sulphuric acid (detection under daylight after heating at $100{ }^{\circ} \mathrm{C}$ for 5-10 minutes) and natural product reagent/polyethylene glycol (detection under $\mathrm{UV}_{366 \mathrm{~nm}}$ for phenolic substances) prepared according to CsONTALA (2004) were used as spraying reagents. Photos of the TLC plates were taken with a Sony $\alpha$ NEX-3 under $\mathrm{UV}_{366 \mathrm{~nm}}$ and visible light.

All extracts were analysed by high performance liquid chromatography (HPLC) with specific gradients for polar and apolar extracts (Supplementary Table S3) on a Shimadzu HPLC (Autosampler Sil-20AC HT, Parallel Double Micro Plunger Type LC-20AD, Prominence degasser DGU-20A $\mathrm{A}_{5}$, HPLC System Controller CBM-20A, HPLC Photo Diode Array Detector SPD-M20-A, Column oven CTO-20AC). All extracts were dissolved in $\mathrm{MeOH}$ by sonication and analysed at a concentration of $5 \mathrm{mg} \cdot \mathrm{ml}^{-1}$. Before injection, the extracts were centrifuged for 5 minutes using an Eppendorf miniSpin. The results were analysed with the software HPLCsolution (Shimadzu, Kyoto, Japan).

For detecting volatile substances, allelopathically active n-butanol ice extracts and DCM ice extracts of all four Chara species were analysed by gas chromatographymass spectrometry (GC-MS) on a Shimadzu GC-2010 gas chromatograph (Shimadzu GCMS-QP2010, column: Phenomenex, Zebron ZB-5, GC Capillary Column, $60 \mathrm{~m}$ x 0.25 $\mathrm{mm} \times 0.25 \mu \mathrm{m}$; carrier gas: helium - flow: $20.2 \mathrm{ml} \mathrm{min}^{-1}$; injection volume: $1 \mu \mathrm{l}$; pressure: $187.7 \mathrm{kPa}$; gradient: $0-90$ min: $60-330^{\circ} \mathrm{C}$ and $90-100 \mathrm{~min}: 330^{\circ} \mathrm{C}$; solvent cut time: 6 $\min$; temperature increase per min: $3{ }^{\circ} \mathrm{C}$; ion source temperature: $250{ }^{\circ} \mathrm{C}$; interface temperature: $270{ }^{\circ} \mathrm{C}$ ). The extracts were dissolved in DCM, centrifuged (Eppendorf miniSpin) and analysed at a concentration of $5 \mathrm{mg} \mathrm{ml}^{-1}$. Results were analysed with the software GCMSsolution (Shimadzu, Kyoto, Japan). Two libraries (WILEY229.LIB, NIST147.LIB) and the Kovats retention index were used for peak identification.

Data analysis. Data were analysed and visualised by using the software packages Sigma Plot 11.0 and 12.0 (Systat Software, San Jose, CA, USA), ImageJ 1.46r (RASBAnd 1997 2014), Microsoft Excel 2011 and PowerPoint 2011, Adobe Photoshop CS6 (Adobe Systems, San Jose, CA, USA) and GNU Image Manipulation Program 2.8.14 - GIMP (KIMBALL et al. 1995-2014).

\section{Results}

\section{Bioassays and Aliivibrio fischeri tests}

The polar ice extracts showed the highest inhibitory activity followed by shoots (Supplementary table S1).
Polar $\mathrm{MeOH}$ and $\mathrm{n}-$ butanol extracts resulted in stronger allelopathic activity than the apolar DCM extracts. As only one DCM extract showed inhibition (Supplementary table S1), all further experiments focused on $\mathrm{MeOH}$ extracts of dried material.

The sensitivity of the target organisms was referred to the amount of tests (\%) which indicated allelopathic effects.

Aliivibrio fischeri was the most sensitive target organism, which was indicated by a negative effect on bioluminescence in more than $50 \%$ of the experiments. It was followed by Cyanobacteria; eukaryotic target algae were least sensitive (Supplementary table S1; Fig. 3 and 4). The bioassays indicated only small intra- and interspecific differences in Chara. When comparing the two collection sites, Chara globularis and Chara rudis showed similar allelopathic activities; Chara aspera and Chara tomentosa resulted in slight differences (Supplementary table S1). The seven most active extracts tested at $20 \mu \mathrm{l}$ for effects on bioluminescence were additionally run at $100 \mu \mathrm{l}$ to estimate dosedependence; at the higher dosage the bioluminescence signal was reduced to around $50 \%$ of the initial signal (data not shown).

Growth of Chlorella vulgaris was neither inhibited by fresh Chara shoots nor by the extracts. Acutodesmus acuminatus showed a similar sensitivity to all four Chara species. C. aspera had the strongest effect on Synechococcus elongatus and Alivibrio fischeri, but less on A. acuminatus and Synechococcus leopoliensis. C. tomentosa strongly inhibited $S$. elongatus and $S$. leopoliensis. C. rudis also caused strong inhibition of Aliivibrio fischeri (Fig. 4).

Aliivibrio fischeri showed the highest sensitivity to DCM extracts of dried Chara material followed

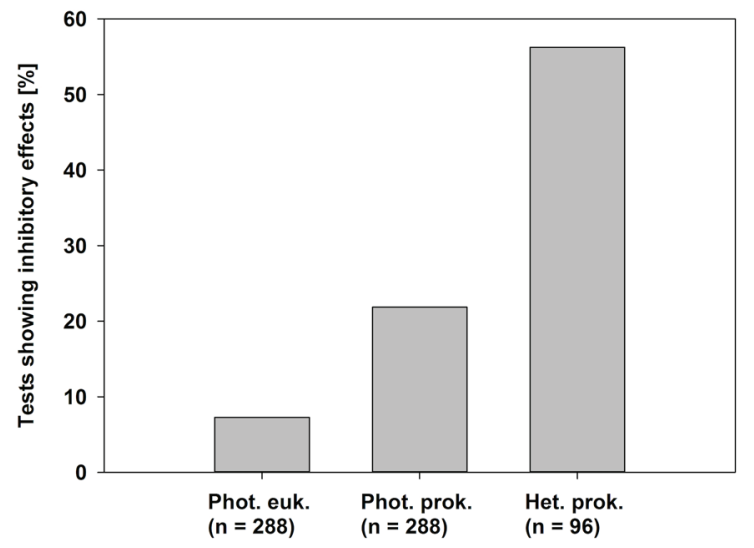

Fig. 3. Proportion of Chara extract bioassay tests (in \% of total experiments) causing inhibition of target groups (presence/absence of inhibition): (n) number of tests including replicates; (Phot. euk.) photoautotrophic eukaryotes (Chlorella vulgaris and Acutodesmus acuminatus); (Phot. prok.) photoautotrophic prokaryotes (Synechococcus elongatus and Synechococcus leopoliensis); (Het. prok.) heterotrophic prokaryote (Aliivibrio fischeri). 
by the polar $n-$ butanol extracts of the ice from lyophilisation (Fig. 5). Apolar DCM extracts of dried material did not lead to any inhibition of photoautotrophs (Fig. 5 and 6). The $n$-butanol ice extracts resulted in the strongest inhibition. $\mathrm{MeOH}$ extracts and $\mathrm{DCM}$ ice extracts caused inhibitions in less than $10 \%$ of tests on photoautotrophs (Fig. 5). Both DCM and $\mathrm{MeOH}$ extracts of air dried material resulted in stronger inhibitions of $A$. fischeri than extracts of lyophilised material (Fig. 6).

In contrast to the $\mathrm{MeOH}$ extracts of air dried material, $\mathrm{MeOH}$ extracts of lyophilised material showed more than twofold inhibitory activity in the bioassays with photoautotrophs (Fig. 6).

C. rudis extracts resulted in the highest number of tests with inhibitory effects $(80 \%)$ on the Proteobacterium $A$. fischeri, followed by $C$. aspera and $C$. globularis (Fig. 7); extracts of $C$. tomentosa were least

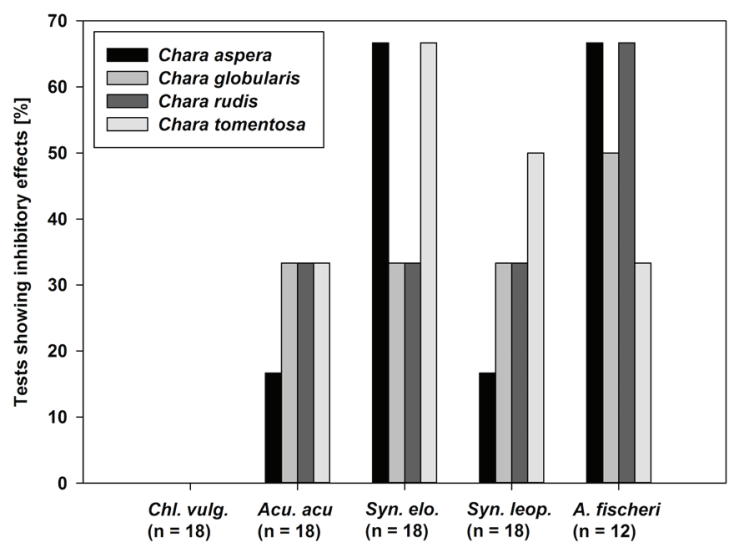

Fig. 4. Inhibitory effects of polar extracts (in \% of total experiments) of Chara species on the different target organisms (presence/absence of inhibition). Both sampling sites summarised: (n) number of tests including replicates; (Chl. vulg.) Chlorella vulgaris; (Acu. acu.) Acutodesmus acuminatus; (Syn. elo.) Synechococcus elongatus; (Syn. leop.) Synechococcus leopoliensis; (A. fischeri) Alivibrio fischeri.

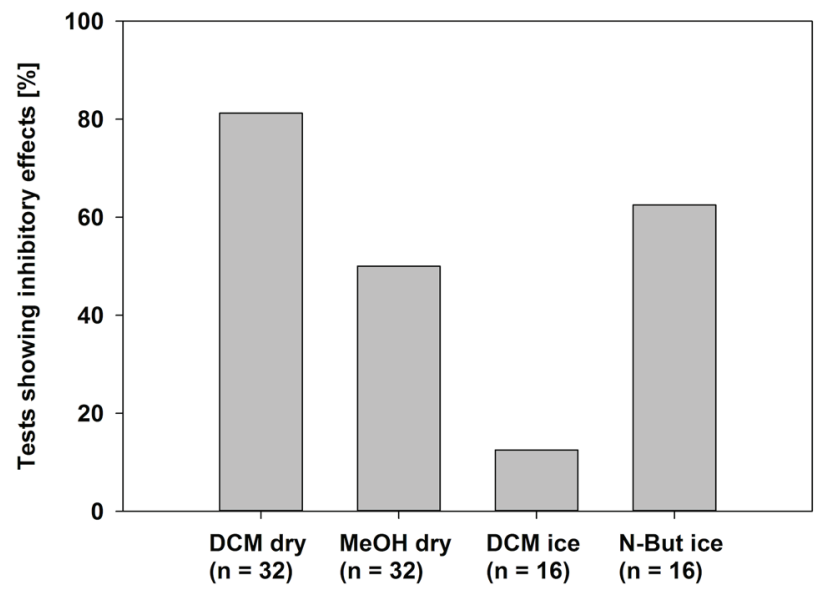

active. C. tomentosa caused the highest amount of all inhibitions (almost 20\%) summarised from all tests on photoautotrophic target organisms followed by C. rudis. C. aspera and C. globularis which showed similar amounts of inhibitory effects in the extract bioassays (Fig. 7).

\section{PAM-measurements}

Figure 8 shows a steep decline of the maximum quantum dark yield (afterwards referred to as "yield") of all four target organisms within the first 20 minutes after incubation with the $\mathrm{MeOH}$ extract of lyophilised Chara tomentosa (Lake Attersee; concentration of 5 $\mathrm{mg} \cdot \mathrm{ml}^{-1}$ ). After 15 to 30 minutes incubation, the yield of $A$. acuminatus, C. vulgaris and S. leopoliensis remained quite constant. $C$. vulgaris regenerated again after 30 minutes and $S$. leopoliensis after 60 minutes, respectively. The yield of $S$. elongatus decreased within the first 90 minutes followed by subsequent, but incomplete recovery.

\section{TLC-experiments}

The fingerprint in the TLC chromatograms (examples of $C$. aspera; Figure 9 and 10) shows that the composition of the extracts from two sampling sites is quite similar. The red bands indicate chlorophylls. The three other stonewort species C. globularis, C. rudis and $C$. tomentosa showed rather identical patterns (data not shown).

\section{HPLC-analyses}

The DCM extracts (see Fig. 11 as an example) showed a very complex pattern of apolar compounds. Despite some differences in the ratio of the analytes, all major components were detected in the lyophilised and air dried samples of Chara aspera from both localities (Lake Attersee, Lake Millstättersee). Within the other

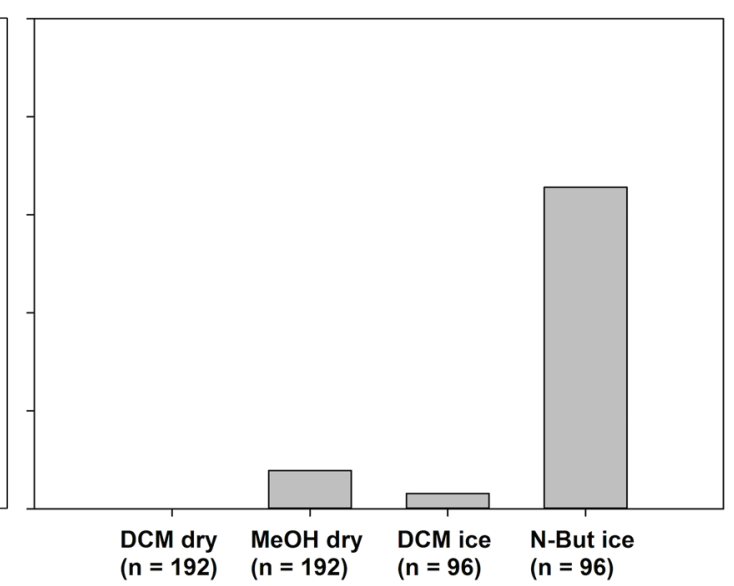

Fig. 5. Inhibition of Aliivibrio fischeri (left) and photoautotrophic target organisms (right; all taxa included) by polar and apolar Chara extracts (in \% of total experiments; presence/absence of inhibition): (n) number of tests including replicates; (DCM dry) dichloromethane extracts of dried material (lyophilisation and air drying summarised); (MeOH dry) methanol extracts of dried material (lyophilisation and air drying summarised); (DCM ice) dichloromethane ice extracts; (N-But ice) n-butanol ice extracts. 


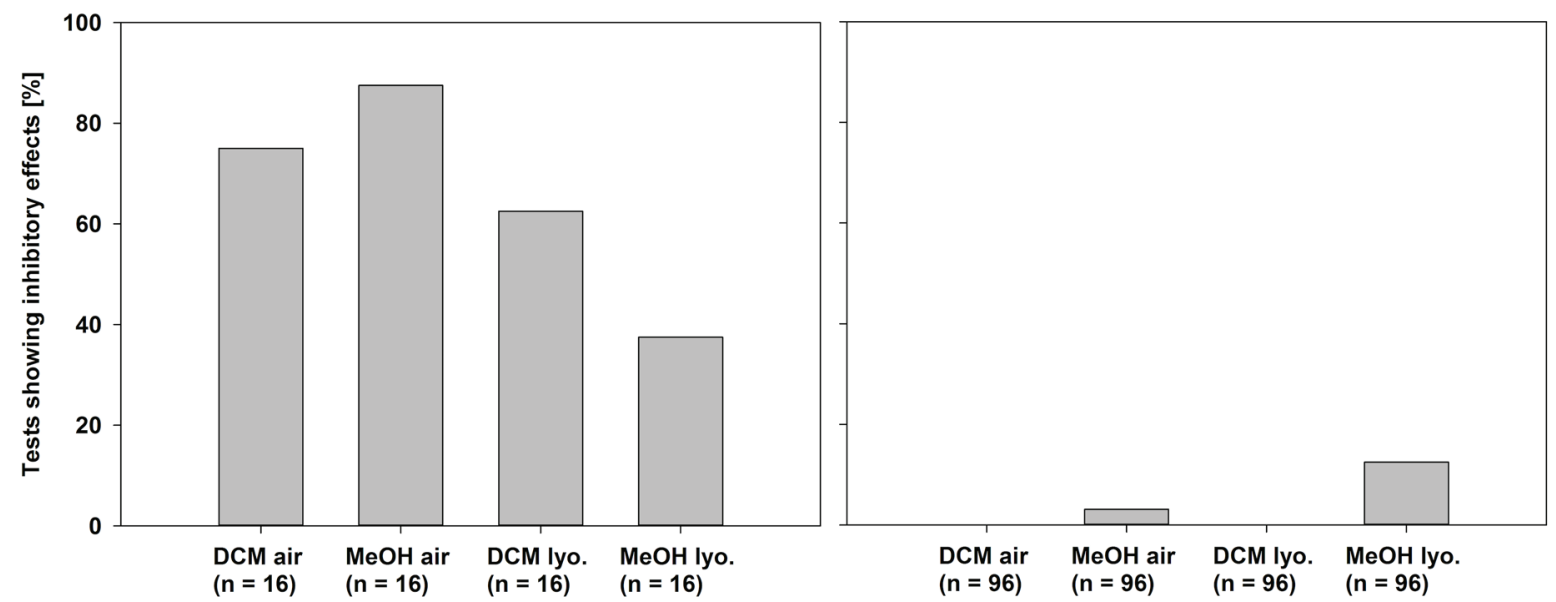

Fig. 6. Comparison of the two drying methods with respect to the inhibitory effects (in \% of total experiments; presence/absence of inhibition) on Aliivibrio fischeri (left) and Acutodesmus acuminatus, Chlorella vulgaris, Synechococcus elongatus and Synechococcus leopoliensis (right). All extract tests, Chara species and sampling sites summarised: (n) number of tests including replicates; (DCM air) dichloromethane extracts of air dried algae; (MeOH air) methanol extracts of air dried algae; (DCM lyo.) dichloromethane extracts of lyophilised algae; (MeOH lyo.) methanol extracts of lyophilised algae.
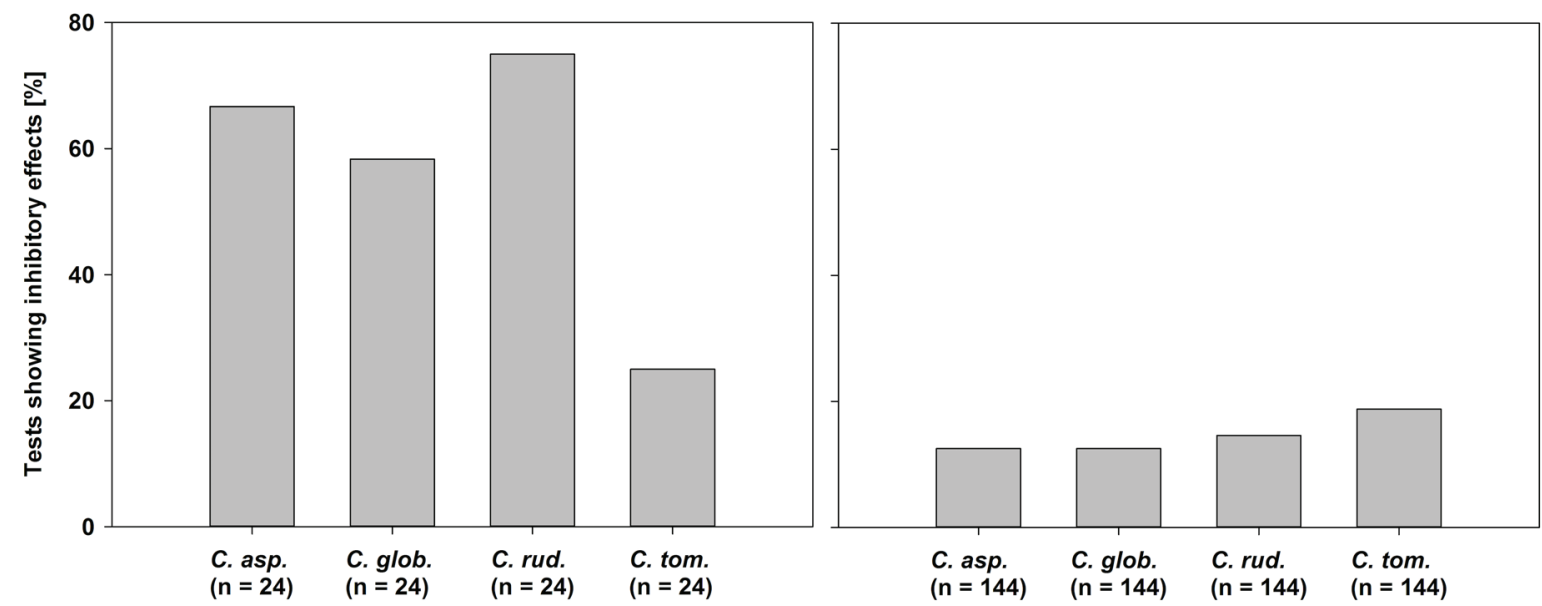

Fig. 7. Inhibitory effects on Aliivibrio fischeri (left) and Acutodesmus acuminatus, Chlorella vulgaris, Synechococcus elongatus and Synechococcus leopoliensis (right) (in \% of total experiments; presence/absence of inhibition). All extracts of all Chara species are included, target organisms are summarised: (n) number of tests including replicates; (C. asp.) Chara aspera; (C. glob.) Chara globularis, (C. rud.) Chara rudis; (C. tom.) Chara tomentosa.

three stonewort species similar patterns were observed (chromatograms not shown). Similarly, the patterns of polar components in the methanolic extracts were congruent. No qualitative, but mainly quantitative differences between the two drying methods and between different origins of the same species were detected by HPLC. The polar n-butanol ice extracts contained components of very high polarity, which could not be separated in the applied HPLC system (chromatograms not shown). The DCM ice extracts - as expected - contained obviously only traces of components, which were below the limit of detection.

\section{GC-MS chromatograms}

The GC-MS chromatograms indicated that active ice extracts contained a complex pattern of compounds with moderate or low volatility. The inactive DCM ice extract from Chara globularis contained similar major components as the active one from Chara rudis, but the concentration of these substances in the inactive was considerably lower (Fig. 12). Despite a detailed comparison of the mass spectra of the detected substances with the available mass spectra databases (WILEY229. LIB, NIST147.LIB), an identification of single compounds was not possible.

\section{Composition of Chara material}

The organic content was rather similar for all stonewort species whereas the proportion of inorganic compounds was highly variable with the exception of $C$. rudis (Fig. 13). C. tomentosa from the Lake Neusiedlersee had the lowest amount of inorganic material. 


\section{Discussion}

This study provides insight into the allelopathic potential of the tested stonewort species on different groups of target organisms. Gross et al. (2007) compared several approaches to detect allelopathic effects of submerged aquatic macrophytes (including Characeae) on phytoplankton and discussed pros and cons of these methods. According to these authors, a single method

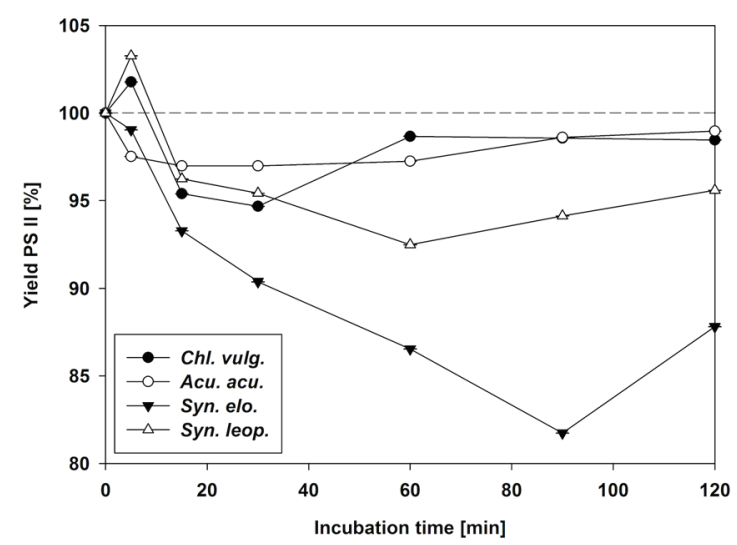

Fig. 8. PAM (Pulse amplitude modulated fluorescence) measurements of the $\mathrm{MeOH}$ extract of lyophilised Chara tomentosa (Lake Attersee). This extract was chosen due to inhibitory effects in preceding experiments. Mean maximum quantum dark yield of PS II (triplicates) is given as percentage of the initial quantum yield (dashed line $=100 \%$ ) before incubating the target organisms with the extract: (Chl. vulg.) Chlorella vulgaris; (Acu. acu.) Acutodesmus acuminatus; (Syn. elo.) Synechococcus elongatus; (Syn. leop.) Synechococcus leopoliensis; (Yield PS II) maximum quantum dark yield of photosystem II. is insufficient for proving allelopathic activity of submerged macrophytes in their natural environment; a combination of both laboratory and field experiments provides much better information. When comparing laboratory and field experiments, differences in strengths of allelopathic effects might be caused by bacterial degradation of labile compounds during the exudation period, fast dilution of allelopathic substances in the surrounding water and the unknown concentration of these substances in the ambient water under in situ conditions (Gross et al. 2007; He et al. 2008).

Collected material of this study had a characteristic pungent, sulphuric smell; Chara tomentosa's aroma resembled garlic. No intraspecific differences were detected from TLC and HPLC patterns indicating that the composition of compounds is independent of environmental conditions. The influence of environmental factors on the amount of synthesized allelochemicals was beyond the scope of the current study, but other studies already demonstrated that light and nutrient supply as well as the presence of certain phytoplankton taxa influence the amount of allelopathic compounds exuded (Reigosa et al. 1999; VAN DonK \& VAN DE Bund 2002; Berger \& Schagerl 2004; Kurashov et al. 2014). We tested the potential of allelopathy in laboratory experiments, but for its impacts in natural environments, additional studies are needed. According to VAn Donk \& VAn de Bund (2002) and Gross (2003a), also seasonal differences might have an effect on the strength of allelopathy (stronger in summer, lower in autumn) which, however, can be neglected in this study because the sampling period for all specimens took place in early summer.

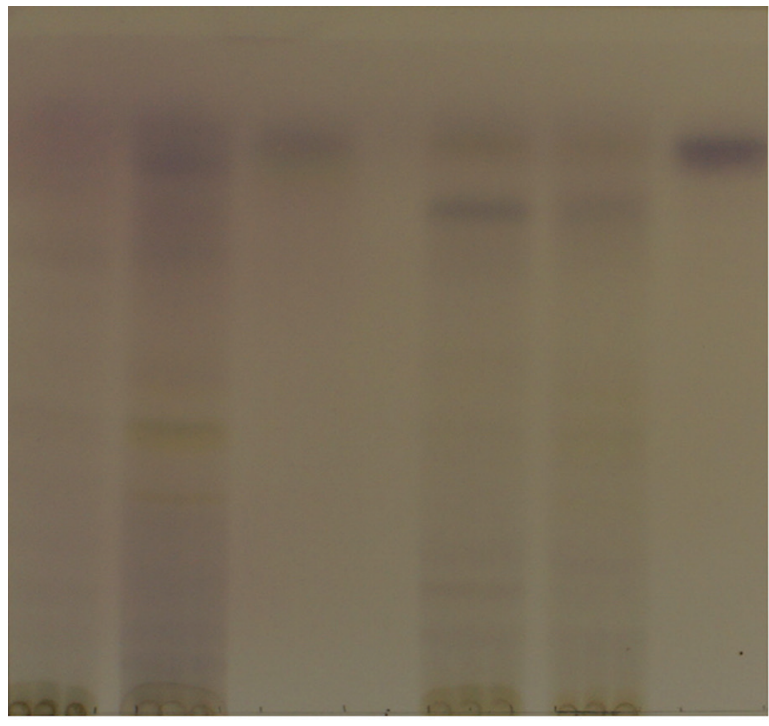

123
4

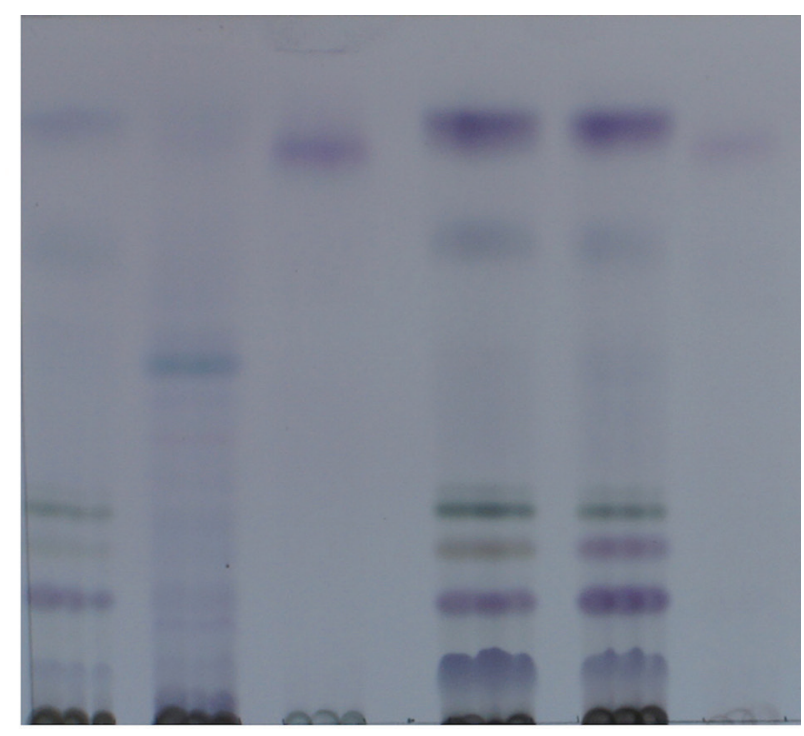

123 4

Fig. 9. Example of TLC chromatograms of Chara aspera extracts under visible light. Detection: anisaldehyde-sulphuric acid reagent and heating at $100{ }^{\circ} \mathrm{C}$ for $5-10$ minutes: (left) MeOH and n-butanol extracts in system A (Supplementary Table S3); (right) DCM extracts in system B (Supplementary Table S3); (1) lyophilised algae Lake Millstättersee; (2) air dried algae Lake Millstättersee; (3) ice extract Lake Millstättersee; (4) lyophilised algae Lake Attersee; (5) air dried algae Lake Attersee; (6) ice extract Lake Attersee. 


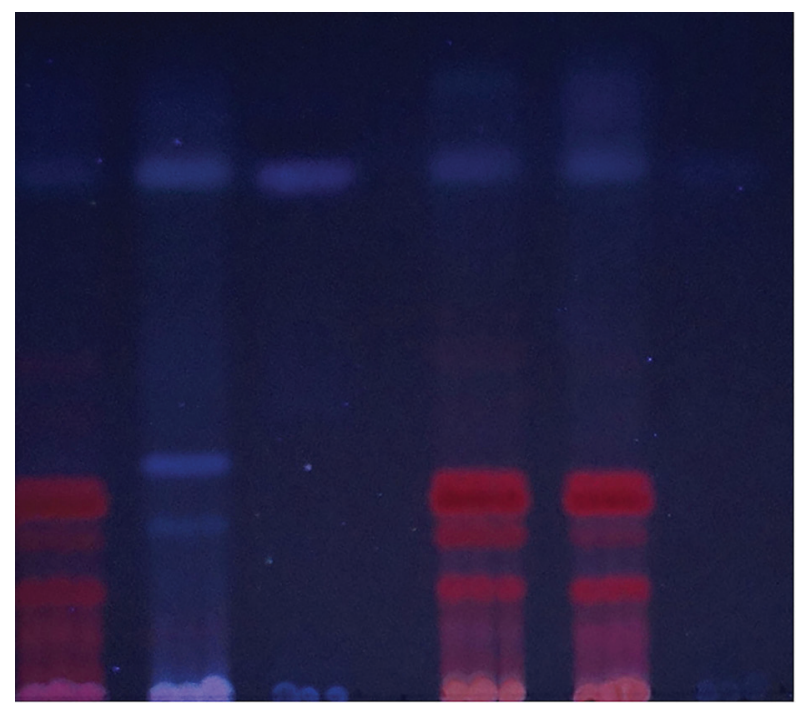

123
4
5
6

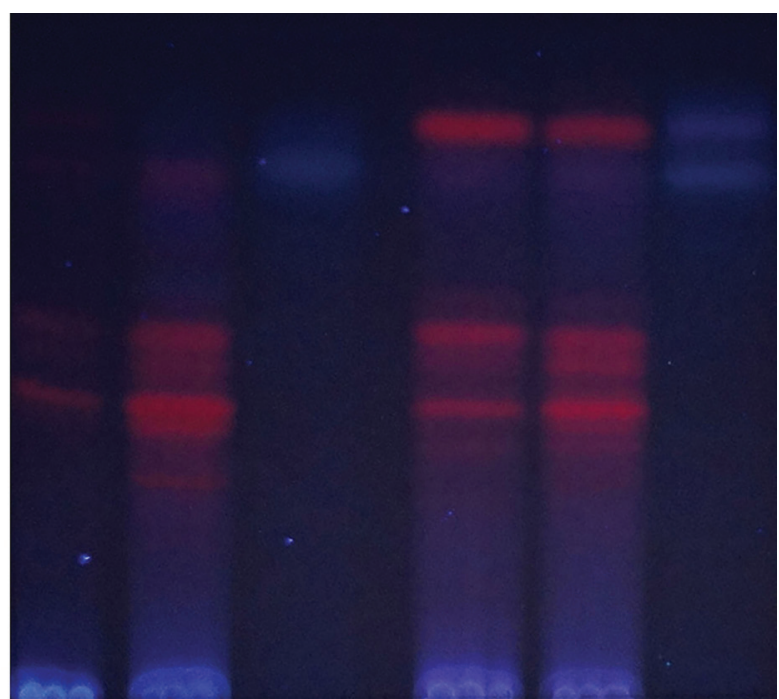

1

2

3

4

5

6

Fig. 10. Example of TLC chromatograms of Chara aspera extracts under $\mathrm{UV}_{366 \mathrm{~m}}$ : Detection natural product reagent and polyethyleneglycol; (left) DCM extracts in system B (Appendix 2); (right) MeOH and n-butanol extracts in system A (Supplementary Table S3); (1) lyophilised algae Lake Millstättersee; (2) air dried algae Lake Millstättersee; (3) ice extract Lake Millstättersee; (4) lyophilised algae Lake Attersee; (5) air dried algae Lake Attersee; (6) ice extract Lake Attersee.

Only Cyanobacteria were inhibited by young Chara shoots, which suggests antibiotic activity of their exudates and which is in accordance with previous studies with similar experimental setups (BERGER \& SCHAGERL 2003). Neither intra-, nor interspecific differences were observable in the tests with living material. We found no increase of the inhibition zone with time, but the zone became more clearly visible; this was also shown by PAKDEL et al. (2013).

Bioassays with extracts resulted in stronger inhibition of Cyanobacteria compared to tested eukaryotes. Similar findings were also reported in some previous studies (BERGER \& SCHAGERL 2003, 2004). It is known, that both Cyanobacteria and stoneworts are able to acclimate to low light conditions (ScHWARZ et al. 1996; Havens et al. 1998; Mur et al. 1999). By colonizing the same microhabitat, competition for light between these two groups might explain the major inhibition of Cyanobacteria. Differences in cell wall components between pro- and eukaryotes probably play a major role for the higher sensitivity of Cyanobacteria (Gross 1999; BERGER \& SCHAGERL 2004). Extracts of dried material did neither affect Chlorella vulgaris nor Acutodesmus acuminatus. Also MulderIJ et al. (2003) did not find any inhibition of Scenedesmus obliquus (TURPIN) KüTZING (neither by Chara globularis nor by Chara contraria A. BRAUn ex KütZING). Bioassays of PAKDEL et al. (2013) also showed no inhibitions of Scenedesmus quadricauda (TURPIN) BREBISSON, whereas LÜRLING et al. (2006) found inhibitions of $S$. obliquus by $C$. globularis. These contradictory results might be explained by species specificity and different methodological approaches.

In contrast to many other studies, which commonly extracted in $\mathrm{MeOH}$ and subsequently divided
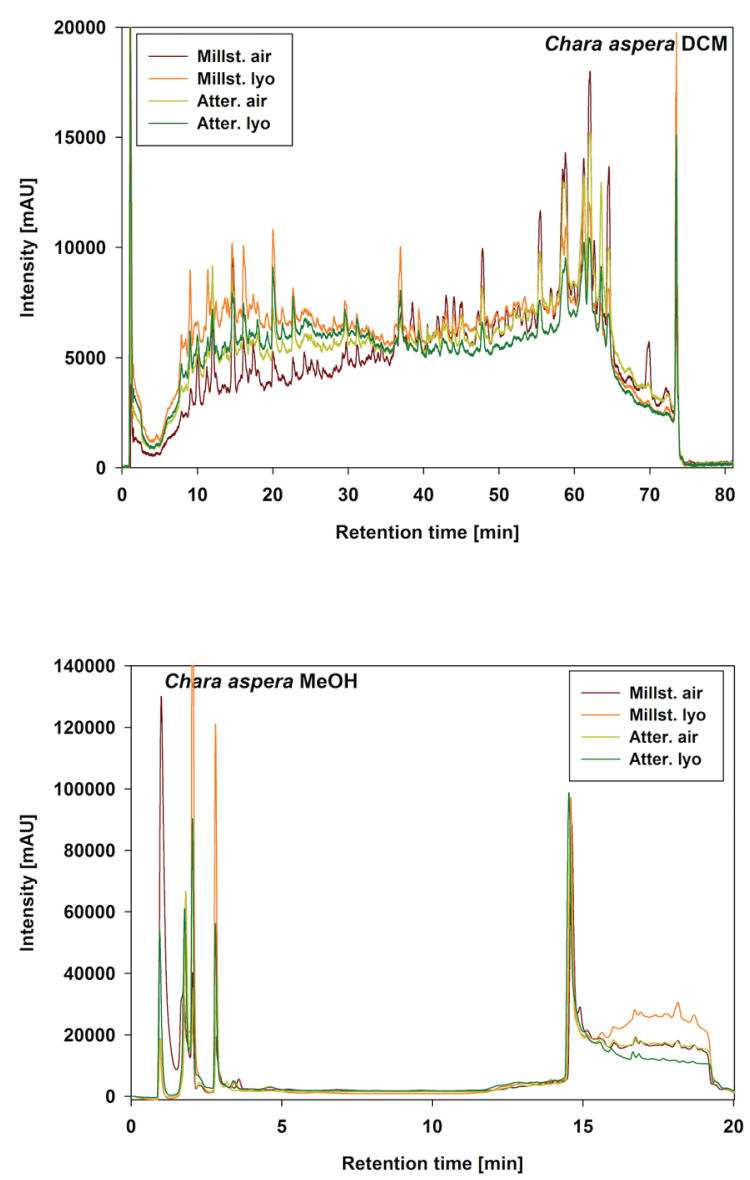

Fig. 11. HPLC chromatograms of Chara aspera extracts (both sampling sites and drying methods) at $254 \mathrm{~nm}$ : (upper) chromatogram of DCM extracts; (lower) MeOH extracts; (DCM) dichloromethane; $(\mathrm{MeOH})$ methanol; (Millst. air) air dried algae from Lake Millstättersee; (Millst. lyo) lyophilised algae from Lake Millstättersee; (Atter. air) air dried algae from Lake Attersee; (Atter. lyo) lyophilised algae from Lake Attersee. 


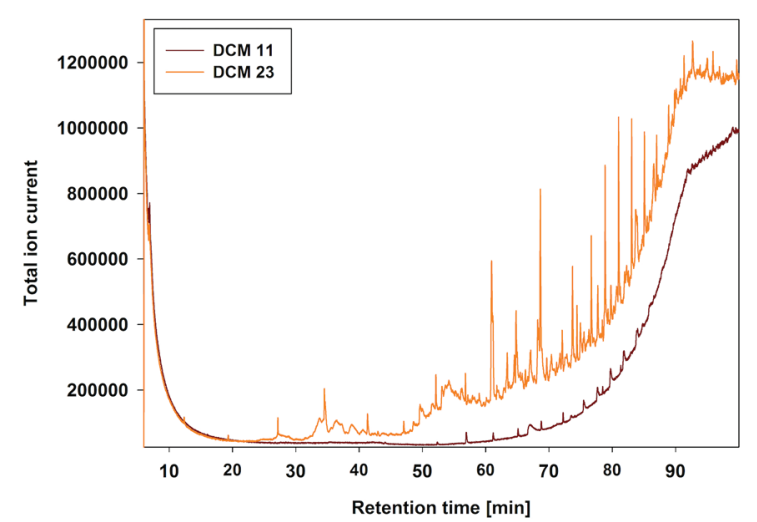

Fig. 12. GC-MS chromatogram of the allelopathically active DCM ice extract from Chara rudis (DCM 23) Lake Erlaufsee (inhibition of ++ ) and inactive one from Chara globularis (DCM 11) Botanischer Garten on photoautotrophic target organisms.

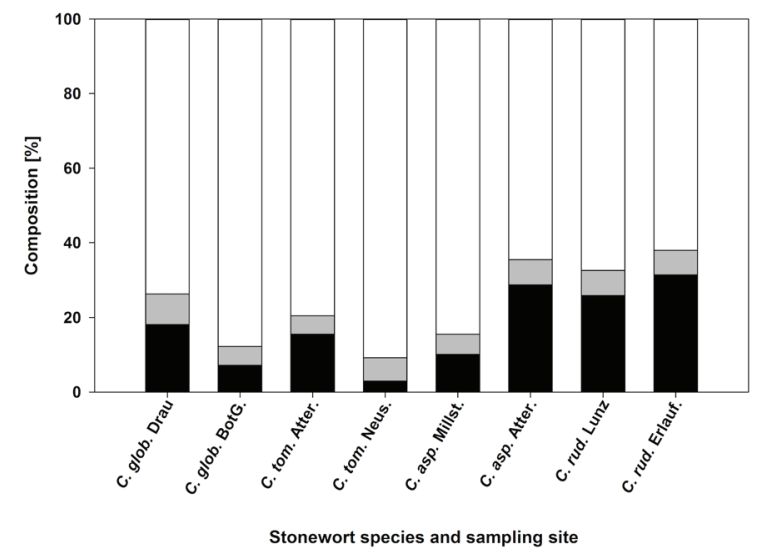

Fig. 13. Composition of Chara: (black) inorganic content; (light grey) organic content; (white) water content; (C. glob. Drau) Chara globularis Obere Drau; (C. glob. BotG.) Chara globularis Botanischer Garten; (C. tom. Atter.) Chara tomentosa Lake Attersee; (C. tom. Neus.) Chara tomentosa Lake Neusiedlersee; (C. asp. Millst.) Chara aspera Lake Millstättersee; (C. asp. Attersee) Chara aspera Lake Attersee; (C. rud. Lunz) Chara rudis Lake Lunzer Untersee; (C. rud. Erlauf.) Chara rudis Lake Erlaufsee.

into moderately lipophilic and hydrophilic fractions (BANKova et al. 2001; Berger \& Schagerl 2003, 2004; PAKDEL et al. 2013), we extracted the same dried material with both apolar and polar solvents (first DCM and then $\mathrm{MeOH}$ ). Apolar DCM extracts of dried Chara material generally did not show any inhibition of photoautotrophic target organisms, which indicated the hydrophilic/polar character of allelochemicals, as polar $\mathrm{MeOH}$ extracts caused several inhibitions.

Aliivibrio fischeri showed a different sensitivity compared to photoautotrophic target organisms, because application of both DCM and $\mathrm{MeOH}$ extracts resulted in a strong decrease of bioluminescence. This marine organism is not naturally present in freshwater systems and probably reacting more sensitive than the freshwater target organisms. Heterotrophic bacteria might possess other nutrient uptake-mechanisms than photoautotrophic bacteria and it is possible that different membrane structures and easily passing low molecular weight (volatile) substances caused the increased sensitivity (Gross 1999).

$\mathrm{N}-$ Butanol ice extracts caused strong inhibitions of Acutodesmus acuminatus, Synechococcus elongatus and S. leopoliensis, which indicated the presence of volatile allelochemicals. Some other studies also suggested that low molecular weight substances could be allelopathically active (ANTHONI et al. 1980; BANKova et al. 2001; VAN Donk \& VAN DE Bund 2002; LÜRLING et al. 2006; KURASHOv et al. 2014). BANKOVA et al. (2001) identified some volatile compounds but did not test them separately for possible inhibitory effects. Chlorella vulgaris seems to be quite resistant against allelochemicals; it was not affected by any of the extracts.

Despite A. acuminatus was not inhibited in the bioassays with fresh Chara material, it was affected by the n-butanol ice extracts. This effect might be caused by higher concentrations of active compounds in the ice extracts than it would occur in situ. It is however a challenge to measure in situ concentrations due to the dilution in natural water bodies (Gross et al. 2007; Kurashov et al. 2014). Since laboratory experiments can hardly simulate the abiotic and biotic in situ parameters, there is an urgent need of additional field studies for testing allelopathic effects (Gross et al. 2007).

A comparison of the two different drying methods lyophilisation and air drying resulted in only small differences in the bioassays with $\mathrm{MeOH}$ extracts, although a strong fishy smell was recognized during air drying at $30{ }^{\circ} \mathrm{C}$. Lyophilised material also showed a characteristic smell, but this was much "fresher". It has to be mentioned here that stoneworts lost their sulphuric smell during both drying methods. Extracts of lyophilised material resulted in a higher number of experiments showing inhibitions in the bioassays with photoautotrophic target organisms than the air dried material, which might indicate a better preservation of algal compounds during lyophilisation.

As several studies suggested that allelochemicals have negative effects on the photosynthesis of target organisms (WIUM-ANDERSEN et al. 1982; Gross 2003a), we included tests of the overall activity of the PSII with one extract, which was shown to be allelopathically active in preceding bioassays. We found a steep decline of the photoautotrophic target organism's maximum quantum dark yield, but also a recovery after 30 and 60 minutes, respectively. This regeneration might be explained by degradation of allelochemicals by the target organisms. Our findings are comparable to allelopathic effects caused by Chara globularis reported by LÜRLING et al. (2006). In our experiments, the two green algae Chlorella vulgaris and Acutodesmus acuminatus regenerated faster than the two Cyanobacteria species. As C. vulgaris was never affected in the bioassays, PAM might be a more sensitive measurement tool concerning short-time bioassays. 
Our findings fit perfectly to the results of BANKOVA et al. (2001). Comparison with GC-MS libraries (WILEY229.LIB, NIST147.LIB) and the Kovats retention index of volatile substances from ice did not provide reliable identification of single compounds. This would require a greater qauntity of extracts and involve fractionation and additional purification steps.

Although two strongly and two weakly inhibiting Chara species were chosen (BERGER \& SCHAGERL 2004), we were not able to clearly distinguish between "strong" and "weak" allelopathic activity. According to Berger \& Schagerl (2004), C. tomentosa and $C$. rudis had lower allelopathic activities than $C$. aspera and $C$. globularis, but they used other photoautotrophic target organisms. Thus species specificity, as already mentioned in several other studies, probably plays a key role in allelopathic interactions (BERGER \& Schagerl 2003; Mulderij et al. 2003; Berger \& SchAGERL 2004; PAKDEL et al. 2013). In situ investigations are still scarce, but they will be essential for providing new and more detailed insights into the complex mechanisms of allelopathy in aquatic environments. Gross et al. (2007) claimed that several combined methods (e.g. in situ dialysis bags and coexistence experiments) should be used for detecting allelopathic effects. Allelochemicals released by Chara are promising antibiotics, which was shown in this and other studies for both heterotrophic and photoautotrophic prokaryotes. BANKOVA et al. (2001) observed antibiotic effects by C. globularis on the human pathogen Staphylococcus aureus RosenBACH in bioassays, which is of interest for in-depth pharmaceutical studies. Besides such potential applications to fight pathogens, cyanobacterial blooms may be combated by using allelochemicals released by stoneworts (PAERL et al. 2001; Hu \& HonG 2008).

\section{Conclusion}

The intra- and interspecific comparison revealed only marginal differences of allelopathic activities. Also a method comparison between air drying and lyophilisation of the algae material showed similar results. The target groups had very different inhibition patterns. A hint for volatile substances, which are allelopathically active, was provided by analysing condensed ice of the lyophilisation process. Allelochemicals had a strong antibiotic effect on both heterotrophic and photoautotrophic bacteria. The strongest inhibition was caused by $\mathrm{MeOH}$ (dry material) and n-butanol (ice extracts) extracts indicating the polar nature of these substances.

\section{ACKNOWLEDGEMENTS}

We thank Andrea Lubich and Christina Sykora (Department of Pharmacognosy, University of Vienna) for their support with HPLC and GC-MS analyses. We are very grateful to the members of the
Kärntner Institut für Seenforschung Klagenfurt for providing stonewort distribution maps, Richard Haider (Biologische Station Illmitz) for sampling assistance and Prof. Ines Fritz as well as Michaela Bauer from the IFA Tulln for the possibility of using their laboratory for the luminescence measurements. Thanks to Jan Steger for many helpful comments. This research did not receive any specific grant from funding agencies in the public, commercial, or not-for-profit sectors.

\section{REFERENCES}

Anthoni, U.; Christophersen, C.; Madsen, J.O.; WiumAndersen, S. \& JaCobsen, N. (1980): Biologically active sulphur compounds from the green alga Chara globularis. - Phytochemistry 19: 1228-1229.

Anthoni, U.; Nielsen, P.H.; Smith-Hansen, L.; Wium-AnDersen, S. \& Christophersen, C. (1986): Charamin, a Quaternary Ammonium Ion Antibiotic from the Green Alga Chara globularis. - The Journal of Organic Chemistry 52: 694-695.

Bankova, V.; Stefanov, K.; Dimitrova-Konaklieva, S.; Keremedchieva, G.; Frette, X.; Nikolova, C.; KujumGIEv, A. \& Popov, S. (2001): Secondary metabolites and lipids in Chara globularis Thuill. - Hydrobiologia 457: 199-203.

Berg, M.S.V.D.; Scheffer, M.; Nes, E.V. \& CoOPs, H. (1999): Dynamics and stability of Chara sp. and Potamogeton pectinatus in a shallow lake changing in eutrophication level. - Hydrobiologia 408/409: 335-342.

Berger, J. \& Schagerl, M. (2003): Allelopathic activity of Chara aspera. - Hydrobiologia 501: 109-115.

Berger, J. \& Schagerl, M. (2004): Allelopathic activity of Characeae. - Biologia, Bratislava 59(1): 9-15.

Blindow, I.; Hargeby, A. \& Andersson, G. (2002): Seasonal changes of mechanisms maintaining clear water in a shallow lake with abundant Chara vegetation. Aquatic Botany 72: 315-334.

Chen, J.; Zhang, H.; Han, Z.; Ye, J. \& Liu, Z. (2012): The influence of aquatic macrophytes on Microcystis aeruginosa growth. - Ecological Engineering 42: 130-133.

Crawford, S.A. (1977): Chemical, physical and biological changes associated with Chara succession in farm ponds. - Hydrobiologia 55: 209-217.

Csontala, A. (2004): Chemische Untersuchung von Metaxya rostrata [Diploma thesis]. - XX pp., University of Vienna, Vienna.

Doblander, K. (2013): Analytik von Inhaltsstoffen von Chara vulgaris und Chara gymnophylla [Diploma thesis]. - XX pp., Leopold-Franzens-University Innsbruck, Innsbruck.

Ercisli, S.; Esitken, A.; Turkkal, C. \& Orhan, E. (2005): The allelopathic effects of juglone and walnut leaf extracts on yield, growth, chemical and PNE compositions of strawberry cv. Fern. - Plant Soil Environment 51: 283-187.

Forsberg, C.; Kleiven, S. \& Willén, T. (1990): Absence of allelopathic effects of Chara on phytoplankton in situ. - Aquatic Botany 38: 289-294.

GaO, Z.; Xu, D.; MenG, C.; ZhanG, X.; Wang, Y.; Li, D.; Zou, J.; Zhuang, Z. \& Ye, N. (2014): The green tide-forming macroalga Ulva linza outcompetes the red macroalga Gracilaria lemaneiformis via allelopathy and fast nutrients uptake. - Aquatic Ecology 48: 53-62. 
Gette-Bouvarot, M.; Mermillod-Blondin, F.; Lemoine, D.; Delolme, C.; Danjean, M.; Etienne, L. \& Volatier, L. (2015): The potential control of benthic biofilm growth by macrophytes - A mesocosm approach. Ecological Engineering 75: 178-186.

Gross, E.M. (1999): Allelopathy in Benthic and Littoral Areas: Case Studies on Allelochemicals from Benthic Cyanobacteria and Submersed Macrophytes. - Principles and Practices in Plant Ecology: 179-199.

Gross, E.M. (2003a): Allelopathy of Aquatic Autotrophs. Critical Reviews in Plant Sciences 22: 313-339.

Gross, E.M. (2003b): Differential response of tellimagrandin II and total bioactive hydrolysable tannins in an aquatic angiosperm to changes in light and nitrogen. - OIKOS 103: 497-504.

Gross, E.M.; Hilt, S.; Lombardo, P. \& MulderiJ, G. (2007): Searching for allelopathic effects of submerged macrophytes on phytoplankton - state of the art and open questions. - Hydrobiologia 584: 77-88.

Havens, K.E.; Phlips, E.J.; Cichra, M.F. \& Li, B.L. (1998): Light availability as a possible regulator of cyanobacteria species composition in a shallow subtropical lake. - Freshwater Biology 39: 547-556.

He, F.; Deng, P.; Wu, X.; Cheng, S.; GaO, Y. \& Wu, Z. (2008): Allelopathic effects on Scenedesmus obliquus by two submerged macrophytes Najas minor and Potamogeton malaianus. - Fresenius Environmental Bulletin 17: 92-97.

Hitr, S. (2006): Allelopathic inhibition of epiphytes by submerged macrophytes. - Aquatic Botany 85: 252256.

Hilt, S.; Beutler, E. \& Bauer, N. (2012): Comparison of methods to detect allelopathic effects of submerged macrophytes on green algae. - Journal of Phycology 48: $40-44$

Hitt, S. \& Gross, E.M. (2008): Can allelopathically active submerged macrophytes stabilise clear-water states in shallow lakes? - Basic and Applied Ecology 9: 422-432.

Hu, H. \& Hong, Y. (2008): Algal-bloom control by allelopathy of aquatic macrophytes - A review. - Frontiers of Environmental Science and Engineering in China 2: $421-438$.

Jeppesen, E.; Jensen, J.P.; SondergaArd, M.; Lauridsen, T.; Pedersen, L.J. \& Jensen, L. (1997): Top-down control in freshwater lakes: the role of nutrient state, submerged macrophytes and water depth. - Hydrobiologia 342/343: 151-164.

JiANG, Z.; GuO, P.; ChANG, C.; GAO, L.; S. LI \& WAN, J. (2014): Effects of Allelochemicals from Ficus microcarpa on Chlorella pyrenoidosa. - Brazilian Archives of Biology and Technology 57: 595-605.

Kimball, S.; Mattis, P. \& GIMP-Entwicklerteam (19952014): GIMP. http://www.gimp.org.

KÖRNER, S. \& NICKLISCH, A. (2002): Allelopathic growth inhibition of selected phytoplankton species by submerged macrophytes. - Journal of Phycology 38: $862-871$.

Krause, W. (1997): Freshwater Flora of Central Europe Charales (Charophyceae). - 202 pp., Fischer, Jena.

Kurashov, E.A.; Krylova, J.V.; Mitrukova, G.G. \& CherNOvA, A.M. (2014): Low-Molecular-Weight Metabolites of Aquatic Macrophytes Growing on the Territory of Russia and Their Role in Hydroecosystems. - Contemporary Problems of Ecology 7: 433-448.
Kusel-Fetzmann, E. \& Schagerl, M. (1992): Verzeichnis der Sammlung von Algen-Kulturen an der Abteilung für Hydrobotanik am Institut für Pflanzenphysiologie der Universität Wien. - Phyton (Horn, Austria) 32: 209-234.

LÜrLing, M.; Van Geest, G. \& Scheffer, M. (2006): Importance of nutrient competition and allelopathic effects in suppression of the green alga Scenedesmus obliquus by the macrophytes Chara, Elodea and Myriophyllum. - Hydrobiologia 556: 209-220.

Maxwell, K. \& Johnson, G.N. (2000): Chlorophyll fluorescence - a practical guide. - Journal of Experimental Botany 51: 659-668.

McCourt, R.M.; Delwiche, C.F. \& Karol, K.G. (2004): Charophyte algae and land plant origins. - Trends in Ecology and Evolution 19: 661-666.

Molisch, H. (1937): Der Einfluss einer Pflanze auf die andere - Allelopathie. - 106 pp., Fischer, Jena.

Mulderi, G.; MooJI, W.M.; SMolders, A.J.P. \& VAn DonK, E. (2005): Allelopathic inhibition of phytoplankton by exudates from Stratiotes aloides. - Aquatic Botany 82: 284-296.

Mulderis, G.; Van Donk, E. \& Roelofs, J.G.M. (2003): Differential sensitivity of green algae to allelopathic substances from Chara. - Hydrobiologia 491: 261271.

Mur, R.; Skulberg, O.M. \& Utkilen, H. (1999): Cyanobacteria in the environment - In: CHORUS, I. \& BARTRAM, J. (eds): Toxic cyanobacteria in water. $-15-40$ pp., E\&FN Spon, London, UK.

ORTNER, A. (2012): Isolierung und Identifizierung sekundärer Inhaltsstoffe aus der Armleuchteralge Chara rudis [Diploma thesis]. - XX pp., Leopold-Franzens-University Innsbruck, Innsbruck.

Paerl, H.W.; R.S. Fulton III; Moisander, P.H. \& Dyble, J. (2001): Harmful Freshwater Algal Blooms, With an Emphasis on Cyanobacteria. - The Science World 1: 76-113.

Pakdel, F.M.; Sim, L.; Beardall, J. \& Davis, J. (2013): Allelopathic inhibition of microalgae by the freshwater stonewort, Chara australis, and a submerged angiosperm, Potamogeton crispus. - Aquatic Botany 110: 24-30.

Pelechata, A.; Pelechaty, M. \& Pukacz, A. (2015): Winter temperature and shifts in phytoplankton assemblages in a small Chara-lake. - Aquatic Botany 124: 10 18.

Rasband, W.S. (1997-2014): ImageJ, U.S. National Institutes of Health, Bethesda, Maryland, USA, http:// imagej.nih.gov/ij/.

Reigosa, M.J.; Sánchez-Moreiras, A. \& GonzÁlez, L. (1999): Ecophysiological Approach in Allelopathy. Critical Reviews in Plant Sciences 18: 577-608.

Rodrigo, M.A.; Rojo, C.; Segura, M.; Alonso-Guillén, J.L.; Martín, M. \& Vera, P. (2015): The role of charophytes in a Mediterranean pond created for restoration purposes. - Aquatic Botany 120: 101-111.

Rojo, C.; Segura, M. \& Rodrigo, M.A. (2013): The allelopathic capacity of submerged macrophytes shapes the microalgal assemblages from a recently restored coastal wetland. - Ecological Engineering 58: 149_ 155.

SAG (2016): SAG Culture Collection Göttingen, Accessed: 21.04.2016.

Schwarz, A.M.; Hawes, I. \& Howard-Williams, C. (1996): 
The role of photosynthesis/light relationships in determining lower depth limits of Characeae in South Island, New Zealand lakes. - Freshwater Biology 35: 69-80.

VAn Donk, E. \& VAN DE Bund, W.J. (2002): Impact of submerged macrophytes including charophytes on phyto- and zooplankton communities: allelopathy versus other mechanisms. - Aquatic Botany 72: 261-274.

Wagner, H. \& Bladt, S. (2001): Plant Drug Analysis - A Thin Layer Chromatography Atlas. - 384 pp., Springer Verlag Berlin Heidelberg, New York.

Wium-Andersen, S.; Anthoni, U.; Christophersen, C. \& Houen, G. (1982): Allelopathic effects on phytoplankton by substances isolated from aquatic macrophytes (Charales). - OIKOS 39: 187-190.

Ye, C.; LiaO, H. \& Yang, Y. (2014): Allelopathic inhibition of photosynthesis in the red tide-causing marine alga, Scrippsiella trochoidea (Pyrrophyta), by the dried macroalga, Gracilaria lemaneiformis (Rhodophyta). - Journal of Sea Research 90: 10-15.

Supplementary material

the following supplementary material is available for this article:

Table S1. Summary of all tests (bioassays with fresh Chara material and extracts).

Table S2. Volatile (a) and polar substances (b) of Characeae.

Table S3. HPLC conditions for the analysis of polar and apolar extracts.

This material is available as part of the online article (http:// fottea.czechphycology.cz/contents)

(C) Czech Phycological Society (2017)

Received August 13, 2016

Accepted October 12, 2016 